\title{
MORFOGENESIS DE HONGOS DEMATIACEOS V: ESTUDIOS BIOQUIMICOS Y ULTRAESTRUCTURALES EN FONSECAEA PEDROSOI Y WANGIELLA DERMATITIDIS Y SUS CORRESPONDIENTES ALBINAS
}

Palabras clave: Morfogénesis, ultraestructura, bioquímica, cepas albinas, Fonsecaea pedrosoi y Wangiella dermatitidis

Key words: Morphogenesis, ultrastructure, biochemistry, albino strains, Fonsecaea pedrosol, Wangiella dermatitidis

\section{RESUMEN}

Se sometió a la acción de los ácido cltrico y clorhídrico a pH = 1,5 una cepa de Fonsecaea pedrosol (CMUR 263/74) y una de Wangiella dermatitidis (CMUR 104/81) productoras de cromoblastomicosis y faeohifomicosis respectivamente, lográndose producir sus mutantes albinas. Estas cepas fueron sometidas a pruebas bioquimicas, de susceptibilidad a agentes antifúngicos, al estudio de su ultraestructura, a la acción de la luz ultravioleta y a ensayos de recuperación en tierras estériles y no estériles.

Se encontraron diferencias en la utilización y en la fermentación de hidratos de carbono, y en la utilización de diversos aminoacidos y vitaminas entre las cepas originales y sus albinas correspondientes.

Las pruebas de susceptibilidad utilizando 5-FC, Ketoconazol y Anfotericina $B$ mostraron diferencias entre éstas. También se observaron variaciones en la estructura de la pared en las cepas incluídas en este estudio, mientras que la luz ultravioleta no demostró producir alteraciones en el crecimiento.

Ambas cepas con sus correspondientes albinas se recuperaron de tierras estériles; en cambio esto no fue posible en las no estériles.
Laura L. Ramos y Alfredo L. Borghi

Departamento de Microbiología (Area Micología) Facultad de Ciencias Bioquímicas y Farmacéuticas. Universidad Nacional de Rosario. Suipacha 531, Rosario (2000), Santa Fe, República Argentina 
Se concluye que la acción de estos ácidos a pH muy bajo, produce cambios en las características bioquímicas, y ultraestructurales en los dos hongos observados.

\section{INTRODUCCION}

A pesar de la relativa frecuencia de la cromoblastomicosis, poco se conoce acerca de la composición química de la pared celular de los agentes productores de esta enfermedad y de los factores que influyen en la relación hospedadorparásito.

En los hongos patógenos, la presencia de melanina (considerada como un factor de resistencia a la lisis por fagocitosis), fue señalada para P. verrucosa (14), este pigmento oscuro forma parte de un complejo protéico de alto peso molecular, ubicado en la pared celular y puede ser secretado al medio durante su desarrollo.

Según Emmons y col. (6), la razón esencial para la patogenicidad de un hongo puede estar expresada en términos generales, en la tolerancia a temperaturas de $35-37^{\circ} \mathrm{C}$, presencia de sistemas enzimáticos, los cuales permiten la parasitación de los tejido del huésped, la exposición continua de este a los propágulos de dispersión (conidios) del hongo. El factor determinante de que algunos hongos patógenos humanos sean dimórficos, puede estar relacionado con la estructura de la pared celular. Manipulando la construcción de la pared celular, los hongos pueden asumir diferentes formas encuadradas en una amplia variedad de funciones incluyendo la penetración al hospedador.

San Blas G. (12), expresa que la pared celular es importante en la regulación de los eventos de contacto entre el parásito y el hospedador y la presencia de otros factores en estos, pueden ser importantes para la invasión del hongo en los tejidos. Esos factores pueden ser internos (capacidad del microorganismo a desarrollar bajo condiciones nutricionales provistas por el tejido hospedador, la producción de toxinas, etc.), o externos (influencia del ambiente a inducir al parásito a sintetizar materiales que de otro modo no pueden ser producidos, mecanismos de defensa del hospedador, etc.). Los factores reguladores en las especies, suelen jugar un rol en la relación hospedador-parásito y la pared fúngica puede ser una primera subestación que regula las señales. La comprensión de estos mecanismos se traduce en un incremento del conocimiento de los eventos
5) F. pedrosoi and $\mathrm{W}$. dermatitidis an their albiness mutants were recovered from sterilized soils. However, only the wild-type strains were recovered from non-sterilized soils.

According to the obtained results, we conclude that the action of these acids at a very low $p H$ produce changes at the biochemical and ultrastructural levels in the two described fungi.

bioquímicos involucrados en la invasión y el daño producido de los tejidos.

Los resultados obtenidos por el tratamiento a $\mathrm{pH}$ ácido de los $\mathrm{F}$. pedrosoi y $\mathbf{W}$. dermatitidis comunicados en un trabajo anterior (10) nos llevó a estudiar comparativamente algunas de las modificaciones bioquímicas y ultraestructurales producidas.

\section{MATERIALES Y METODOS.}

1) Pruebas bioquímicas.

a Test nutricional Trichophyton Agar (Difco) (7)

Se utilizó este test para determinar los requerimientos nutricionales entre $\mathbf{F}$. pedrosoi, $\mathbf{W}$. dermatitidis y sus correspondientes albinas midiendo el diámetro de sus colonias.

\section{b. Efecto de las distintas fuentes de carbono y nitrógeno en el crecimiento fúngico}

Se realizaron las técnicas de auxanograma para hidratos de carbono y sustancias nitrogenadas según Rippon (11), y la de fermantación de sustancias hidrocarbonadas según Wickerham (15) modificado por Bracalenti y Col. (3).

\section{2) Pruebas de susceptibilidad con agentes antifúngicos.}

La determinación de 5-Fluorocitosina (5-FC) se realizó según la técnica dada por Smith y col. (13) y la Anfotericina B y Ketoconazol según Negroni R. (9).

\section{3) Estudio de la ultraestructura.}

Las dos cepas de estudio con sus correspondientes albinas se fijaron en glutaraldehído al $3 \%$ en buffer de fosfato $\mathrm{O}, 1 \mathrm{M} \mathrm{pH}=7,4$, luego, en 
tetróxido de osmio al $1.5 \%$ en buffer de fosfato, seguido de impregnación en bloque con acetato de uranilo al $2 \%$. Deshidratación en alcohol decreciente en óxido de propileno. Inclusión en Epon 812 , corte con ultramicrótomo Porter blue MT2B y coloración de contraste con citrato de plomo según Reynolds.

Observación en microscopio electrónico JeolJem 100 C.

\section{Estudio de la velocidad de crecimiento}

- Para los hongos de desarrollo filamentoso se realizó la curva de crecimiento sembrando en los medios de Agar-Sabouraud Glucosa (ASG) y Agar-Papa-Dextrosa (APD) a $27^{\circ}$ C. y $37^{\circ}$ C. durante 19 días y los resultados se expresaron midiendo el diámetro de la colonia.

- En tubos de hemólisis que contenían $2 \mathrm{~cm}^{3}$ de caldo Sabouraud-Glucosa se agrego $0,1 \mathrm{~cm}^{3} \mathrm{de}$ una suspensión de $\mathbf{W}$. dermatitidis en agua destilada estéril que contenían $4 \times 10^{7}$ levaduras $/ \mathrm{cm}^{3}$, incubándose a $27^{\circ} \mathrm{C}$ y y $37^{\circ} \mathrm{C}$. La determinación del peso seco se realizó a $105^{\circ} \mathrm{C}$. haciéndose pesadas cada 48 horas llegando a peso constante a los 15 días, considerando hora cero, los tubos recién inoculados.

\section{5) Acción de la luz ultravioleta.}

Las colonias desarrolladas en los medios ASG y APD de $F$. pedrosoi, $W$. dermatitidis y sus correspondientes albinas se colocaron a $15 \mathrm{~cm}$. de distancia de la luz ultravioleta (Sterisol F 1140 Original Hanan NN 15/44 UK entre 200-300 nm) durante $1,5,10,30,90$ minutos y 4 horas de exposición. Luego se sembraron en el medio de ASG para observar la acción de la luz ultravioleta en cuanto al crecimiento de estos hongos.

6) Recuperación de las cepas de F. pedrosoi, W. dermatitidis y sus correspondientes albinas en tierras estériles y no estériles.

.Se sembraron' en placas de Petri $10 \mathrm{~g}$. de tierra estéril y no estéril, agregándole $100 \mathrm{mg}$. de una suspensión de micelio de $F$. pedrosoi y su albina y por otro lado $10^{6}$ células levadurifor$\mathrm{mes} / \mathrm{cm}^{3}$ de $\mathbf{W}$. dermatitidis y su albina incubándolas a $27^{\circ} \mathrm{C}$ y a los 10 días se tomaron muestras de las placas de tierra estéril y no estéril por cada hongo, repitiéndose lo mismo a los 20 días.
La técnica de procesamiento fue la siguiente: se colocaron los $10 \mathrm{~g}$. de tierra nombrados anteriormente en $19 \mathrm{~cm}^{3}$ de agua destilada estéril en un erlenmeyer de $250 \mathrm{~cm}^{3}$ al que se le agregaron una gota de Tween 80 . Se agitó 15 minutos y se dejó reposar 10 minutos. Se realizaron diluciones de esta solución madre hasta $1 / 128$. Se tomó $1 \mathrm{~cm}^{3}$ de cada dilución y se colocó en una placa Petri con 0,1 $\mathrm{cm}^{3}$ de Rosa de Bengala, $0,1 \mathrm{~cm}^{3}$ de una solución $\left(50 \mathrm{~g} / \mathrm{cm}^{3}\right)$ de cloranfenicol y $10 \mathrm{~cm}^{3}$ de APD, incubándose a $27^{\circ} \mathrm{C}$ durante 10 días.

Se observó el grado de recujiración que se obtuvo en las placas.

\section{RESULTADOS.}

\section{1) Pruebas bioquímicas.}

\section{a) Test nutricional de Trichophyton Agar.}

Los resultados de este test mostraron que la cepa albina de F. pedrosoi creció mejor que su original en medios con caseína, caseína-tiamina y caseína-ácido nicotínico y muy poco en medios con $\mathrm{NH}_{4} \mathrm{NO}_{3}$ como fuente nitrogenada.

Con respecto a W. dermatitidis se observó mejor crecimiento de su cepa albina en los medios conteniendo caseína-inostol, caseína-inostol-tiamina, caseína-tiamina, caseína-ácido nicotínico y $\mathrm{NH}_{4} \mathrm{NO}_{3}$-histidina.

b) Efecto de las distintas fuentes de carbono $y$ nitrógeno en el crecimiento fúngico.

\section{- Auxanograma de hidratos de carbono.}

Las únicas diferencias observadas fueron la utilización de rafinosa por parte de $\mathbf{W}$. dermatitidis albina, mientras que su correspondiente pigmentada utilizó celobiosa; en cuanto a la utilización de sustancias carbonadas por $\mathbf{F}$. pedrosoi y su correspondiente albina no mostraron diferencia alguna.

\section{- Auxonograma de sustancias nitrogenadas.}

W. dermatitidis y $F$. pedrosoi con sus correspondientes albinas no mostraron diferencias en la utilización de sustancias nitrogenadas.

- Fermentación de sustancias hidrocarbonadas.

La cepa de $\mathbf{W}$. dermatitidis albina fermentó glucosa, maltosa y sacarosa mientras que $\mathbf{W}$. dermatitidis no fermentó ninguno de los azúcares empleados. 
2) Pruebas de susceptibilidad con agentes antifúngicos: 5-FC, Anfotericina B y Ketoconazol.

Los resultados obtenidos con esta experiencia mostraron que el poder fungistático para $\mathbf{F}$. pedrosoi con 5-FC es de $50 \mathrm{ug} / \mathrm{cm}^{3}$ y con Ketoconazol de $100 \mathrm{ug} / \mathrm{cm}^{3}$, mientras que el poder fungicida con 5 FC fue nulo para esas concentraciones y para Ketoconazol fue total a la concentración de 100 $\mathrm{ug} / \mathrm{cm}^{3}$.

Para F. pedrosoi y su albina con Anfotericina $B$ el poder fungistático fue nulo para la máxima concentración igual que su poder fungicida.

Las observaciones realizadas sobre $W$. dermatitidis y su albina mostraron que el poder fungistático y fungicida fueron nulos para los tres antifúngicos probado a esas concentraciones.

\section{3) Estudio de la ultraestructura.}

El estudio de la ultraestructura de F. pedrosoi y W. dermatitidis mostró una pared rugosa con dos capas: una externa muy rugosa y densa y una interna gruesa, poco densa. Sus mutantes albinas mostraron la pérdida de la capa B2, lugar en que se produce la melanización. Fotos $1,2,3,4$.

4) Estudio de la velocidad de crecimiento.

Tabla № 1

Diámetro de las colonias (cm) a $27^{\circ}$ C y $37^{\circ} \mathrm{C}$ después de 19 días de incubación en los medios de ASG y APD.

\begin{tabular}{|c|c|c|c|c|}
\hline \multirow{3}{*}{ CEPAS } & \multicolumn{4}{|c|}{ Medios de Cultivo } \\
\hline & \multicolumn{2}{|c|}{ ASG } & \multicolumn{2}{|c|}{ APD } \\
\hline & $27^{\circ} \mathrm{C}$ & $37^{\circ} \mathrm{C}$ & $27^{\circ} \mathrm{C}$ & $37^{2} \mathrm{C}$ \\
\hline F. pedrosoi & 2.1 & 1.4 & 2.3 & 1.5 \\
\hline $\begin{array}{l}\text { F. pedrosoi } \\
\text { (var. albina) }\end{array}$ & 3.3 & 2.5 & 0.9 & 0.6 \\
\hline $\begin{array}{l}\text { W. dermatitidis } \\
\text { (var. albina) }\end{array}$ & 3.0 & 0,6 & 3.0 & 0.6 \\
\hline
\end{tabular}

Se observa en Tabla № 1 que no hubo diferencias con respecto a la temperatura y los medios utilizados en $\mathbf{F}$. pedrosoi, mientras que su variedad albina tuvo mejor desarrollo en ASG que en APD a ambas temperaturas, siendo la óptima de $27^{\circ} \mathrm{C}$.

Con respecto a W. dermatitidis (var. albina) no hubo diferencias en cuanto a los medios empleados y la temperatura óptima fue de $27^{\circ} \mathrm{C}$.

\section{5) Acción de la luz ultravioleta.}

Las cepas estudiadas, y sus albinas que fueron expuestas a la radiación ultravioleta no tuvieron diferencias significativas con respecto al crecimiento en el medio de ASG.
6) Recuperación de las cepas de F. pedrosoi, $W$. dermatitidis y sus albinas en tierras estériles y no estériles.

Bajo las condiciones de trabajo expuestas anteriormente, las cepas albinas solamente fueron recuperadas de tierra estéril mientras que las cepas pigmentadas lo fueron de tierra estéril y no estéril hasta la dilución $1 / 128$ ensayada.

\section{DISCUSION Y CONCLUSIONES.}

En un trabajo anterior (10) se sometió a la acción del ácido clorhídrico y cítrico a $\mathrm{pH}=1,5$ una cepa de F. pedrosoi (CMUR 263/74) y una de W. dermatitidis (CMUR 104/81) productoras de 
cromoblastomicosis y faechifomicosis obteniéndose sus correspondientes mutantes albinas y que a través de sucesivos subcultivos nunca revirtieron a sus formas originales. En dicho trabajo también se analiz6 la macro y micromorfología de estas cepas albinas comparadas con sus respectivas cepas patrones y la patogenicidad en ratones.

Las pruebas bioquímicas mostraron diferencias entre la cepa albina y su correspondiente pigmentada ya sea en la utilización de sustancias carbonadas, nitrogenadas y en la fermentación de hidratos de carbono para W. dermatitidis. Con respecto a $\mathbf{F}$. pedrosoi no se encontraron diferencias con su cepa albina en cuanto a la capacidad de utilización de sustancias carbonadas y nitrogenadas

El test de Trichophyton Agar (Difco) se utilizó para caracterizar la capacidad metabólica de las cepas estudiadas encontrándose que las cepas albinas utilizaron con más eficacia vitaminas y aminoácidos esenciales para su desarrollo que las cepas testigo. En cambio, la cepa albina de F. pedrosoi tuvo menor capacidad para utilizar $\mathrm{NH}_{4} \mathrm{NO}_{3}$.

${ }^{4}$ Las pruebas de susceptibilidad a los tres antifúngicos empleados demostraron que para $\mathbf{W}$. dermatitidis testigo ninguno de ellos produjo efecto en cambio su albina fue inhibida por Anfotericina B.

Con respecto a F. pedrosoi: Anforericina B. inhibió la cepa testigo y su albina, 5-FC no produjo inhibición y Ketoconazol inhibió solamente a la cepa testigo.

La presumible distribución de la melanina en las paredes de los conidios fue revelada por estudios con microscopía electrónica (5). De acuerdo con nuestras observaciones podemos inferir que la acción de los ácidos cítrico y clorhídrico a pH muy ácidos actúan a nivel de la capa $B$, fundamental. mente en la región B2 donde se produce la melanización y por consiguiente una de las causas de la aparición de las mutantes albinas podría deberse a dicha acción.
La acción de la luz ultravioleta sobre la parte visible del espectro $(380-720 \mathrm{~nm})$ tiene relativamente poco efecto sobre el crecimiento vegetativo de los hongos, sin embargo puede tener acciones significativas sobre la esporulación. Estas pueden ser mucho más pronunciadas sobre el crecimiento vegetativo, cuando son producidas por la radiación ultravioleta en la región de 200-300 um, causando mutaciones y daño letal al DNA. Se forman uniones covalentes entre nucleótidos de pirimidina adyacentes dando dímeros de timina y citosina, los cuales inhiben la síntesis de DNA normal. Si las células son subsecuentemente expuestas a las radiaciones entre 360 y $420 \mathrm{~nm}$, muchos de los danos inducidos por la luz ultravioleta son revertidos debido a que la actividad de enzimas específicas pueden descomponer los dímeros formados in situ. La melanización confiere un alto grado de protección contra el daño producido por la luz ultravioleta sobre el protoplasma (4). Esta situación se comprobó con las cepas testigo de ambos hongos, los cuales no sufrieron daño después de la exposición a la radiación ultravioleta.

Sus correspondientes albinas tampoco lo sufrieron, probablemente debido a los mismos mecanismos reparadores señalados anteriormente.

Los microorganismos inoculados en suelos estériles se desarrollaron rápidamente obteniéndose poblaciones de gran tamaño, inoculaciones similares en suelos no estériles derivan en un pobre desarrollo y frecuentemente las especies introducidas son eliminados en un período de días o semanas. La diferencia es enteramente el resultado de interacciones biológicas de naturaleza injuriosa (1) (2) (8). Las cepas testigo fueron recuperadas tanto de tierra estéril como de no estéril, mientras que las mutantes albinas solo de las tierras estériles, lo que indicó que estas cepas no resisten las condiciones de competencia del ambiente.

\section{BIBLIOGRAFIA.}

\footnotetext{
1) ALEXANDER, M. (1977): Introduction to soil Microbiology, 410-421, 2ds.ed. John Wiley and Sons. New York. Chichester. Brisbane. Toronto.

2) BLOONFIELD, B. J. AND ALEXANDER, M. (1967): J. Bacteriel. 93: 1276-1280.
}

3) BRACALENTI, B. J. C. DE: BORGHI, A. L.; ALVARES, D. P. Y LOPEZ, C. E. (1981): Identificación de levaduras de importancia clínica. Facultad de Ciencias Bioquímicas y Farmacéuticas. Universiđad Nacional de Rosario. 
4) DEACON, J. C. (1984): Introduction to Modern Mycology Basic Microbiology. Vel. 57: 112-113. Seacon edition. Ed. K. F. Wilkinson-Blackwell Scientific Publications. Oxford. London. Boston. Palo Alto. Melbourn.

5) BURRELL, L. W. (1964): The conposition and structura of walls of dark fungus spore. Mycopathol. Mycol. App. 23: 339-345.

6) EMMONS, C. W.; BINGORD, C. H.; UTZ, P. J. AND KWON-CHUNG, K. J. (1977): Medical Mycology, 592. 3ra. Ed. Lea and Febiger, Philadelphia.

7) GERG, L. CAMP L. B. (1957): Routine nutritional tests for the identification of dermatophytes. J. Bact. 74: 113121.

8) KUO, M. J. AND ALEXANDER M. (1967): J. Bacteriol. 94: 624-629.

9) NEGRONI, R. (1977): Acción antifúngica de nuevos compuestos imidazólicos. Actas de las VIIl Jornadas y Primer Congreso Argentino de Micología, 166-174.
10) RAMOS, L., BORGHI, A. L. (1987): Morfogénesis de hongos dematiáceos IV: Influencia del medio ácido sobre la morfología de Fonsecasea pedrosoi y Wangiella dermatitidis. Presentando en el III Congreso Argentino de Micología y XIII Jornadas Argentinas de Micología. Mar del Plata 28-31/10/87. República Argentina.

11) RIPPON, J. W. (1982): Medical Mycology. The pathogenic fungi and the pathogenic Actinomycotes, 774-775, W. B. Saunders Company, Philadelphia. London. Toronto. México City. Río de Janeiro. Sydney. Tokio.

12) SAN BLAS, G. (1982): The cell well of fungal human pathogens: its possible role in host-parasite ralationships. Mycopathologia 79: 159-184.

13) SMITH, SHADOMY Y ANA ESPINEL INGROFF (1982): Pruebas de susceptibilidad con agentes antifúngicos. Manual de Microbiología Clínica. Lennett E., 776784, 3ra. eđitión. Lennett E., Balows A., Hansler W. Truvant J. Editorial Médica Panamericana.

14) SZANISZLO, P. J., COOPER, B. H. AND VOGES H. S. (1972): Chemical composition of the hyphal walls of three chromomycosis agents. Sabouraudia 10: 94-102.

15) WICKERHAM, L J. (1951): Taxonomy of yeast. Technical Bulletin № 1029 V. S. Department of Agricultura. Washington D. C. 


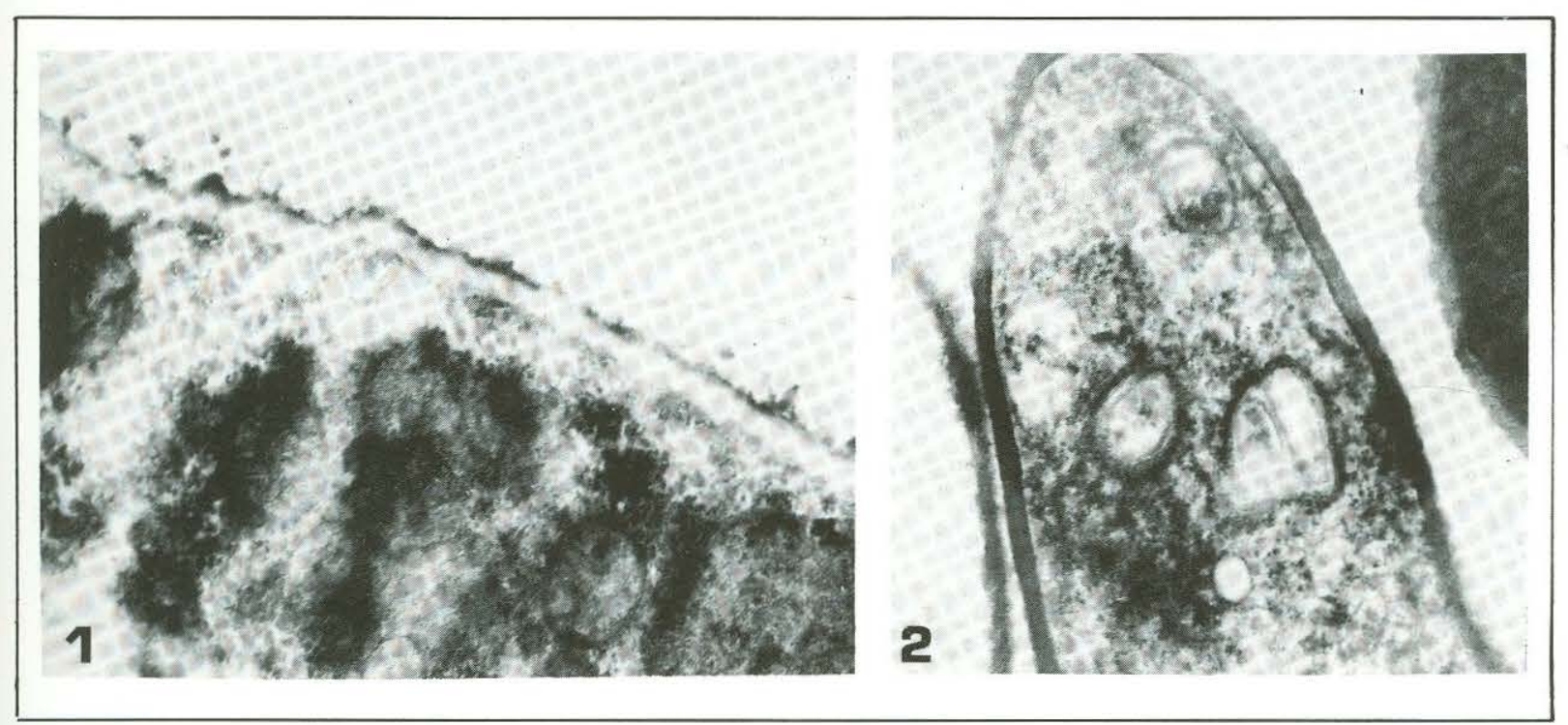

Foto № 1: F. pedrosoi por 150.000: se observa la pared celular rugosa con dos capas, una externa muy rugosa, densa; y una interna gruesa, poco densa. Foto № 2: F. pedrosoi albina por 100.000: se observa una única capa externa, densa en un filamento.

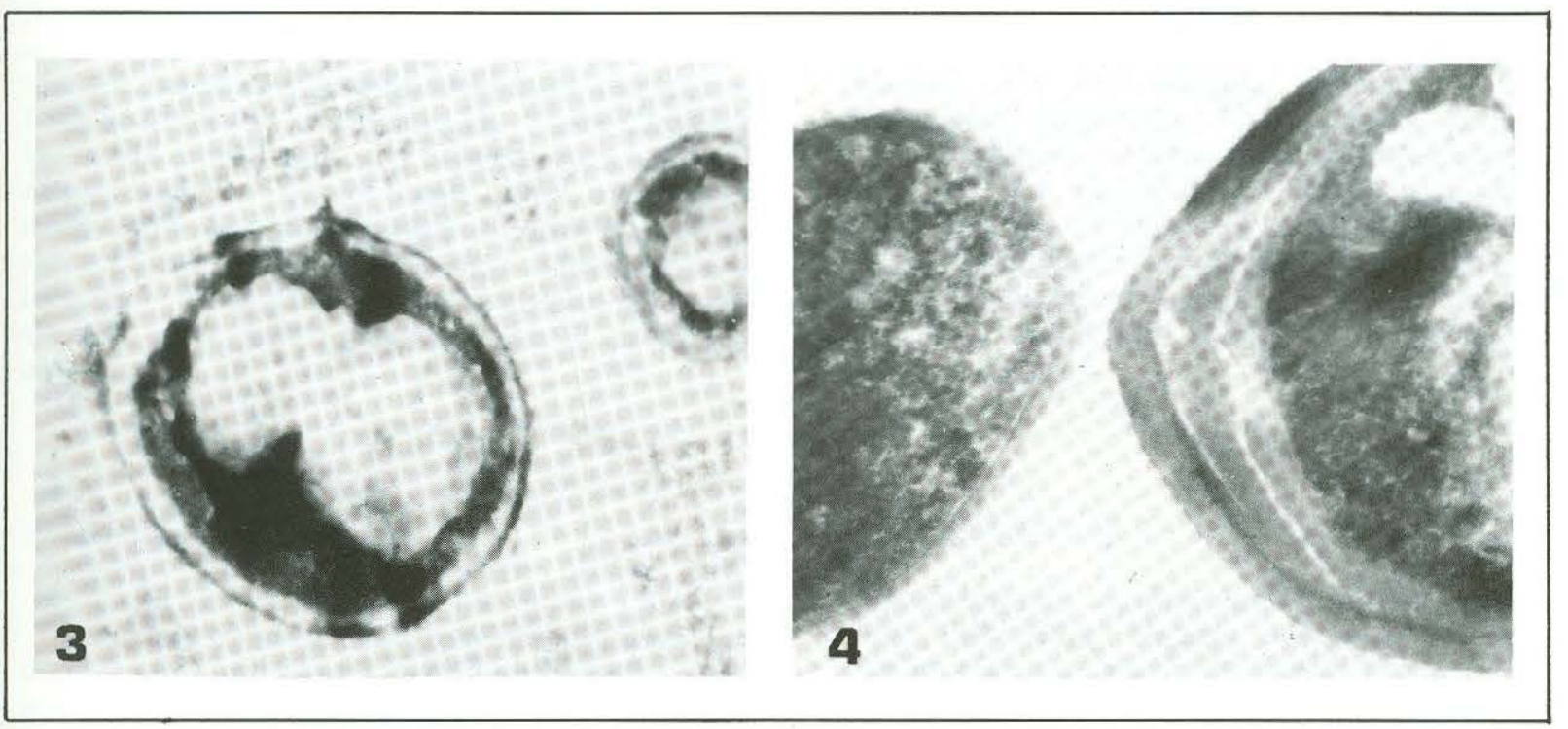

Foto $\mathrm{N}^{0}$ 3: W. dermatitidis por 37.500: se observa en la pared celular una capa externa regularmente densa, sugosa, y una capa interna muy poco denșa. Foto Ne 4: W. dermatitidis albina por 100.000: se observa la formación de tres capas. 